\title{
How do the general population behave with facemasks to prevent
}

\section{COVID-19 in the community?}

Colin DESCHANVRES, MD ${ }^{1,2}$; Thomas HAUDEBOURG, $\mathrm{PhD}^{1}$; Nathan PEIFFER-

SMADJA, MD ${ }^{3}$; Karine BLANCKAERT, MD ${ }^{1}$; David BOUTOILLE, MD, PhD²;

Jean-Christophe LUCET, MD, $\mathrm{PhD}^{3,4}$; Gabriel BIRGAND' PharmD, $\mathrm{PhD}^{1,5}$

${ }^{1}$ Centre d'Appui à la Prévention des Infections Associées aux Soins (CPias) des Pays de la Loire, Centre

Hospitalo-Universitaire de Nantes, Nantes, France

${ }^{2}$ Service de Maladies Infectieuses, Centre Hospitalo-Universitaire de Nantes, Nantes, France

${ }^{3}$ INSERM, IAME, UMR 1137, F-75018 Paris, France; Univ Paris Diderot, Sorbonne Paris Cité, F-75018

Paris, France

${ }^{4}$ AP-HP, Hôpital Bichat - Claude Bernard, Infection Control Unit, F-75018 Paris, France

${ }^{5}$ NIHR Health Protection Research Unit in Healthcare Associated Infection and Antimicrobial Resistance at Imperial College London, Hammersmith Campus, Du Cane Road, London, UK

Corresponding author: Gabriel Birgand, 5 rue du Professeur Yves Boquien 44093 Nantes, France (gbirgand@gmail.com). 


\section{Key Points}

Question: What is the frequency and quality, and their associated factors, of the use of facemasks in general populations of different socio-spatial backgrounds?

Findings: Among 3354 observations, 56.4\% of individuals wore a facemask, either a surgical mask (56.8\%) or a cloth mask (43.2\%), and the mask was correctly positioned in $75.2 \%$ of cases. Correct use of facemasks was more common in rural and indoors areas, individuals wearing cloth masks, and among those aged $>40$ years.

Meaning: Health authorities should promote the use of cloth masks, engage young people in this process, and consider the mandatory universal masking. 


\section{ABSTRACT}

IMPORTANCE The appropriate use of facemasks, recommended or mandated by authorities, is critical to protect the community and prevent the spread of COVID-19.

OBJECTIVE To evaluate the frequency and quality of facemask use in general populations of different socio-spatial backgrounds.

DESIGN A multi-site observational study carried out from 25 June 2020 to 21 July 2020.

SETTING The observations were carried out in 43 different locations in a region in the west of France, representing various areas: rural and urban, indoor and outdoor, and in areas where masks were mandated or not. An observer was positioned at a predetermined place, facing a landmark, and collected information about the use of facemasks and socio-demographic data.

PARTICIPANTS All individual passing between the observer and the landmark were included.

EXPOSURE The observer collected information on whether a mask was worn, the type of mask used, the quality of the positioning, gender, and the age category of each individual.

MAIN OUTCOMES AND MEASURES The main outcomes were the use of a facemask and the quality of the positioning. Factors associated with these outcomes were identified.

RESULTS A total of 3354 observations were recorded. A facemask was worn by $56.4 \%(n=1892)$ of individuals, varying from $49 \%(n=1359)$ in non-mandatory areas and 91.7\% $(n=533)$ in mandatory areas, including surgical facemasks $(56.8 \%, n=1075)$ and cloth masks $(43.2 \%, n=817)$. The facemask was correctly positioned in $75.2 \%(n=1422)$ of cases. The factors independently associated with wearing a facemask were being indoors (adjusted odds ratio [aOR], 0.37; 95\% confidence interval [CI], 0.31-0.44), being in a mandatory area (aOR, 0.14; 95\%CI, 0.10-0.20), female gender (aOR, 0.57; 95\%CI, 0.49-0.66), and age $>40$ years (aOR, 0.54; 95\%CI, 0.46-0.63). The factors independently associated with correct mask position were rural location (aOR, 0.76; 95\% CI, 0.97-0.98), being in an indoor area (aOR, 0.49; 95\%CI, 0.38-0.65), use of a cloth mask (aOR, 0.65; 95\%CI, 0.52-0.81), and age >40 years (aOR, 0.61; 95\%CI 0.49-0.76).

CONCLUSIONS AND RELEVANCE Information campaigns should promote the use of cloth masks. Young people in general and men in particular are the priority targets. Simplifying the rules to require universal mandatory masking seems to be the best approach for health authorities. 


\section{INTRODUCTION}

Since the emergence of the Coronavirus (COVID-19) epidemic, wearing a facemask in the community has become commonplace. In many countries, facemasks are mandatory in crowded areas where social distancing cannot be respected and are recommended outdoors. ${ }^{1}$ Appropriate use of facemasks is critical for protection in the community to prevent the spread of COVID-19. ${ }^{2}$ However, the constraints and discomfort caused in a population unfamiliar with this protective equipment can result in suboptimal use, leading to ineffective protection against COVID-19. Observation and quantification of the quality of facemask use is required to: assess the level of respiratory protection, inform decision makers on the effectiveness of measures, and identify levers for behavior change. We evaluated the frequency and quality of facemask use in general populations with different socio-spatial backgrounds, and contextual factors associated with the appropriate use of the facemask.

\section{METHODS}

From June 25, 2020, to July 21, 2020, we conducted observations in 13 cities and 43 different locations in the Pays de la Loire region in western France with a population of 3.8 million (Supplementary Figure 1). The observations were performed in various areas: rural and urban (cities with $>10,000$ and with $<10,000$ inhabitants), indoors (shopping centers, train stations) or outdoors (shopping streets), and in areas where masks were or were not mandatory. The observer was positioned in a predetermined place, facing a landmark, and all people passing between the observer and the landmark were included. For each individual, the researcher recorded if a facemask was worn, the type of facemask, and the quality of facemask positioning. The facemask was considered incorrectly worn if it was in one of the positions defined in Table 1. For each observation session, information on the time, location, and mandatory status was recorded. In addition, demographic characteristics were collected, including the gender and age category $(21-40,41-65$, and $>65$ years). The data were collected on a smartphone using a Google form. Contingency tables and chi-squared tests were used for categorical variables. Unadjusted relative risks (ORs) were determined and 95\% confidence intervals $(95 \% \mathrm{CI})$ were computed. Multiple logistic regression was performed. Variables 
associated with $\mathrm{p}$ values $<0.25$ in the bivariate analysis were entered into the model to obtain maximum likelihood estimates. These analyses were performed using $\mathrm{R}$ version 3.6.1.

\section{RESULTS}

A total of 3354 observations were performed during 55 sessions (Table 2): 1639 (49\%) observations were performed indoors and 1715 (51\%) outdoors. The ratio of males to females was 0.73 , and $44.6 \%(n=1495)$ were aged $21-40$ years, $35.3 \%(n=1184)$ were aged $41-65$ years, and $20.1 \%(n=675)$ were $>65$ years.

A facemask was worn by $56.4 \%(n=1892)$ of individuals, varying from $40 \%(n=679)$ outdoors and $74 \%$ $(n=1213)$ indoors, 59\% $(n=720)$ in rural areas, 55\% $(n=1172)$ in urban areas, 49\% $(n=1359)$ in nonmandatory areas, and $91.7 \%(n=533)$ in mandatory areas. With regard to the type of facemask worn, 56.8\% $(n=1075)$ wore a surgical facemask and 43.2\% (n=817) wore a cloth mask. Among the 1892 individuals wearing a facemask, $75.2 \%(n=1422)$ were wearing it correctly. Of the 470 masks positioned incorrectly, 141 (30\%) were below the chin and $130(27.7 \%)$ below the nose. Overall, $42.4 \%(n=1422$ of 3354$)$ of the population studied was effectively protected.

In the multivariate analysis, facemasks were significantly more often worn indoors (adjusted odds ratio [aOR], $0.37 ; 95 \% \mathrm{CI}, 0.31-0.44 ; \mathrm{p}<0.001)$ and in mandatory areas (aOR, 0.14; 95\%CI, 0.10-0.20; $\mathrm{p}<0.001)$. Facemasks were significantly less frequently worn by males (aOR, 1.75; 95\%CI, 1.51-2.04; $\mathrm{p}<0.001)$ and by younger individuals aged 21-40 years $(\mathrm{aOR}, 2.28 ; 95 \% \mathrm{CI}, 1.83-2.85 ; \mathrm{p}<0.001)$ and those aged $41-65$ years (aOR, 1.34; 95\%CI, 1.08-1.68; p=0.008) (Table 2).

Among the individuals wearing a facemask, correct positioning was significantly higher in rural (aOR, 0.75 ; 95\%CI, 0.57-0.97; $\mathrm{p}=0.03)$ and indoor areas $(\mathrm{aOR}, 0.49 ; 95 \% \mathrm{CI}, 0.38-0.65 ; \mathrm{p}<0.001)$. The use of cloth masks in comparison with surgical masks was significantly associated with correct positioning (aOR, 0.65; 95\%CI, $0.52-0.81 ; \mathrm{p}<0.001)$. Incorrect positioning was significantly associated with the younger age group (21-40 years) $(\mathrm{OR}, 1.47$; 95\%CI, 1.10-1.98; $\mathrm{p}=0.01)$ (Table 3). 


\section{DISCUSSION}

In a post lockdown context with large clusters of COVID-19 cases leading to a potential second wave, less than half of the individuals were correctly protected in the general population. Unsurprisingly, the mandatory process was the most powerful variable associated with increased use of facemasks. The mandatory approach may represent the best political lever to increase the level of facemask use in the general population.

Among the people wearing a facemask incorrectly, the most commonly observed positions were below the chin or below the nose. Following the mandate to wear a facemask in shops and indoor public areas, people going from one shop to another are not keeping their facemask on. These observations suggest that facemasks are being handled and repositioned by individuals going between two mandatory areas, perhaps due to respiratory discomfort. These behaviors could lead to an increase in the risk of transmission, particularly through hand contamination. This fact is important due to the difficulty in complying with hand hygiene measures when putting the facemask on and taking it off. Mandatory universal masking, even in the absence of scientific evidence outdoors, has the advantage of simplifying the measure and avoiding misuse.

The positioning of cloth masks was significantly better in comparison with surgical facemasks. People wearing cloth masks may correspond to a sub-population of individuals engaged by choosing their mask, the cloth, and pattern. On the other hand, the characteristics of surgical facemask (impersonal, single use, more expensive, potentially less comfortable to wear) decrease compliance with best practices. Good quality cloth masks that can be customized with various sizes and patterns may adapt better to the face, making them more comfortable, and may lead to better engagement by users. ${ }^{3}$

The use of facemasks was significantly lower and more often worn incorrectly in the population $<40$ years and in males independently of non-use of the mask. This finding is consistent with the increase in COVID-19 cases in the younger population during the post lockdown period. ${ }^{4,5}$ The lack of clinical impact associated with the social factors that applied during the lockdown potentially led to lower adherence to preventive measures by the young population during the summer break. These populations represent a target for authorities in their information campaigns to optimize the protection of the general population. Facemasks were worn correctly by those in rural areas compared with urban areas. In small cities, people are living together as part of an 
identifiable network, with significant social norms and better individual behaviors. In contrast, in urban populations, individuals are anonymous, with less reference to norms and altruistic measures.

To our knowledge, this study is the first to quantify the frequency and quality of the use of facemasks in the general population. However, the visual and potentially subjective evaluation of the criteria should be acknowledging as potential limitations. Despite the inclusion of a range of situations at the regional scale, the generalizability is questionable.

\section{CONCLUSION}

Information campaigns should promote the use of cloth masks. Young people in general and men in particular are the priority targets. Simplifying the rules to require universal mandatory masking seems to be the best approach for health authorities.

\section{Declarations}

Ethics Approval and Consent to Participate: Not applicable.

Consent for Publication: Not applicable.

Availability of Data and Material: Data sharing not applicable to this article because no datasets were generated or analyzed during the study.

Funding: The study was funded by Agence Régionale de Santé (ARS) of Pays de la Loire. Gabriel Birgand (GB) was funded by the National Institute for Health Research Health Protection Research Unit (NIHR HPRU) in Healthcare Associated Infection and Antimicrobial Resistance at Imperial College London in partnership with Public Health England (PHE). The views expressed are those of the author(s) and not necessarily those of the NHS, the NIHR, the Department of Health or PHE. GB has received an Early Career Research Fellowship from the Antimicrobial Research Collaborative at Imperial College London and acknowledges the support of the Welcome trust. RA is supported by a NIHR Fellowship in knowledge mobilization. The support of ESRC as part of the Antimicrobial Cross Council initiative supported by the 
medRxiv preprint doi: https://doi.org/10.1101/2020.09.18.20195669; this version posted September 18, 2020. The copyright holder for this preprint (which was not certified by peer review) is the author/funder, who has granted medRxiv a license to display the preprint in perpetuity.

It is made available under a CC-BY-NC-ND 4.0 International license .

seven UK research councils and the support of the Global Challenges Research Fund are gratefully acknowledged.

Acknowledgments: None.

Competing Interests: The authors declare that they have no competing interests. 


\section{REFERENCES}

1. Haut conseil de santé publique (HCSP). Préconisations du Haut Conseil de la santé publique relatives à l'adaptation des mesures barrières et de distanciation sociale à mettre en œuvre en population générale, hors champs sanitaire et médico-social, pour la maîtrise de la diffusion du SARS-CoV-2 n.d.:39. 2020. Accessed July 08, 2020.

2. Chu DK, Akl EA, Duda S, et al. Physical distancing, face masks, and eye protection to prevent person-to-person transmission of SARS-CoV-2 and COVID-19: a systematic review and metaanalysis. Lancet. 2020;395:1973-1987. https://doi.org/10.1016/S0140-6736(20)31142-9.

3. van der Westhuizen H-M, Kotze K, Tonkin-Crine S, Gobat N, Greenhalgh T. Face coverings for covid-19: from medical intervention to social practice. BMJ 2020;370:m3021. https://doi.org/10.1136/bmj.m3021.

4. Goldstein E, Lipsitch M. Temporal rise in the proportion of younger adults and older adolescents among coronavirus disease (COVID-19) cases following the introduction of physical distancing measures, Germany, March to April 2020. Eurosurveillance 2020;25(17). https://doi.org/10.2807/1560-7917.ES.2020.25.17.2000596.

5. Santé Publique France. Point épidémiologique hebdomadaire du 20 août 2020. 2020. https://www.santepubliquefrance.fr/maladies-et-traumatismes/maladies-et-infectionsrespiratoires/infection-a-coronavirus/documents/bulletin-national/covid-19-point-epidemiologique-du20-aout-2020. Accessed Aug 22, 2020. 
Table 1. Definitions for the Qualitative Evaluation of Mask Position.

\section{Correct positioning}

Correct: bar fitted on the nose, mask stretched to the chin, the fasteners are all used and are not crossed

\section{Incorrect positioning}

Below the nose: the mask only covers the mouth, the nose is visible

Below the mouth: the mask is lowered, placed under the nose and mouth at the chin or neck

On the forehead: the mask is raised and placed over the eyes

On one ear: the mask is worn only by a rubber band hanging from one ear

Worn backward (outside in): the colored side of the mask is inside rather than outside

No adjustment of the bar on the nose: the mask is placed on the nose but is not fitted around it

Not stretched under the chin: the mask does not cover the chin

Cross fasteners (twisted elastic, strap from top to bottom): the elastic bands or straps cross

Partial attachment with only one strap on each side: only the top straps are tied

Long hair falling on the mask or face (not tied): long hair covers part of the mask 
medRxiv preprint doi: https://doi.org/10.1101/2020.09.18.20195669; this version posted September 18, 2020. The copyright holder for this preprint (which was not certified by peer review) is the author/funder, who has granted medRxiv a license to display the preprint in perpetuity.

It is made available under a CC-BY-NC-ND 4.0 International license .

Table 2. Description of the Study Population, with Demographic Characteristics, Frequency and Qualitative Characteristics of Use of Masks.

\begin{tabular}{|c|c|c|c|c|c|}
\hline \multirow[t]{2}{*}{ Characteristics } & \multirow[t]{2}{*}{ Overall, n (\%) } & \multicolumn{2}{|c|}{ Outdoor, n (\%) } & \multicolumn{2}{|c|}{ Indoor, n (\%) } \\
\hline & & Urban & Rural & Urban & Rural \\
\hline Number of observations & 3354 & 1165 & 550 & 974 & 665 \\
\hline \multicolumn{6}{|l|}{ Gender } \\
\hline Female & $1943(57.9)$ & $705(60.5)$ & $303(55.1)$ & $550(56.5)$ & $385(57.9)$ \\
\hline Male & $1411(42.1)$ & $460(39.5)$ & $247(44.9)$ & $424(43.5)$ & $280(42.1)$ \\
\hline \multicolumn{6}{|l|}{ Age category } \\
\hline $21-40$ years & 1495 (44.6) & $705(60.5)$ & $141(25.6)$ & $456(46.8)$ & $193(29)$ \\
\hline $41-65$ years & $1184(35.3)$ & $373(32)$ & $190(34.5)$ & $365(37.5)$ & $256(38.5)$ \\
\hline$>65$ years & $675(20.1)$ & $87(7.5)$ & $219(39.8)$ & $153(15.7)$ & $216(32.5)$ \\
\hline \multicolumn{6}{|l|}{ Time of day } \\
\hline Morning & $1454(43.4)$ & $269(23.1)$ & $400(72.7)$ & $328(33.7)$ & $457(68.7)$ \\
\hline Afternoon & $1900(56.6)$ & $896(76.9)$ & $150(27.3)$ & $646(66.3)$ & $208(31.3)$ \\
\hline \multicolumn{6}{|l|}{ Mask mandated } \\
\hline No & $2773(82.7)$ & $1165(100)$ & $550(100)$ & $510(52.4)$ & $548(82.4)$ \\
\hline Yes & $581(17.3)$ & $0(0)$ & $0(0)$ & $464(47.6)$ & $117(17.6)$ \\
\hline \multicolumn{6}{|l|}{ Presence of a facemask } \\
\hline No & $1462(43.6)$ & $732(62.8)$ & $304(55.3)$ & $235(24.1)$ & $191(28.7)$ \\
\hline Yes & $1892(56.4)$ & $433(37.2)$ & $246(44.7)$ & $739(75.9)$ & $474(71.3)$ \\
\hline \multicolumn{6}{|c|}{ Type of facemask $(\mathrm{n}=1892)$} \\
\hline Surgical facemask & $1075(56.8)$ & $266(61.4)$ & $131(53.3)$ & $419(56.7)$ & $259(54.6)$ \\
\hline Cloth mask & $817(43.2)$ & 167 (38.6) & $115(46.7)$ & $320(43.3)$ & $215(45.4)$ \\
\hline
\end{tabular}


medRxiv preprint doi: https://doi.org/10.1101/2020.09.18.20195669; this version posted September 18, 2020. The copyright holder for this preprint (which was not certified by peer review) is the author/funder, who has granted medRxiv a license to display the preprint in perpetuity.

It is made available under a CC-BY-NC-ND 4.0 International license .

Quality of mask positioning $(\mathrm{n}=1892)$

Correct

Incorrect

Incorrect positioning $(n=470)$

Below the mouth

Below the nose

Cross straps

Not adjusted on the nose

Hair down on face

Partial mask attachment with strap

Not stretched under the chin

On one ear

On the forehead

Worn backward

$1422(75.2)$

$264(61)$

$191(77.6) \quad 576(77.9)$

$391(82.5)$

$470(24.8)$

169 (39)

$55(22.4)$

$163(22.1)$

$83(17.5)$

$141(30)$

$130(27.7)$

61 (13)

$43(9.1)$

$33(7)$

$35(7.4)$

$13(2.8)$

$10(2.1)$

$3(0.6)$

$1(0.2)$
82 (48.5)

$14(25.5)$

40 (24.5)

$23(41.8) \quad 37(22.7)$

6 (10.9)

$31(19)$

$16(19.3)$

$8(4.7)$

10 (5.9)

$3(5.5)$

$24(14.7)$

$17(10.1)$

$5(9.1)$

$5(3.1)$

$6(7.2)$

9 (5.3)

$1(1.8)$

$13(8)$

$12(14.5)$

$1(0.6)$

2 (3.6)

$4(2.5)$

$3(3.6)$

$0(0)$

$0(0)$

$1(0.6)$

$0(0)$ 
Table 3. Univariate and Multivariable Analysis of Factors Influencing the Use and the Visual Correct Position of Facemask Fit.

\begin{tabular}{|c|c|c|c|c|c|c|c|c|c|c|c|c|}
\hline Factors & Facemask & $\begin{array}{c}\text { No } \\
\text { facemask }\end{array}$ & $\begin{array}{c}\text { Univariate OR } \\
(95 \% \mathrm{CI})\end{array}$ & $\mathbf{p}$ & $\begin{array}{c}\text { Multivariate } \\
\text { aOR }(95 \% \text { CI })\end{array}$ & $\mathbf{p}$ & $\begin{array}{l}\text { Correct } \\
\text { position }\end{array}$ & $\begin{array}{c}\text { Incorrect } \\
\text { position }\end{array}$ & $\begin{array}{c}\text { Univariate OR } \\
\text { (95\% CI) }\end{array}$ & $\mathbf{p}$ & $\begin{array}{c}\text { Multivariate } \\
\text { aOR }(95 \% \text { CI })\end{array}$ & $\mathbf{p}$ \\
\hline Number & $1892(56.4)$ & $1462(43.6)$ & & & & & $1422(75.2)$ & $470(24.8)$ & & & & \\
\hline \multicolumn{13}{|l|}{ Area } \\
\hline Urban & $1172(54.8)$ & $967(45.2)$ & Reference & & Reference & & 840 (71.7) & $332(28.3)$ & Reference & & Reference & \\
\hline Rural & $720(59.3)$ & $495(40.7)$ & $0.83(0.72-0.96)$ & 0.012 & $0.85(0.71-1.02)$ & 0.075 & $582(80.8)$ & $138(19.2)$ & $0.6(0.48-0.75)$ & $<0.001$ & $0.75(0.57-0.97)$ & 0.03 \\
\hline \multicolumn{13}{|l|}{ Location } \\
\hline Outdoor & $679(39.6)$ & $1036(60.4)$ & Reference & & Reference & & $455(67)$ & $224(33)$ & Reference & & Reference & \\
\hline Indoor & $1213(74)$ & $426(26)$ & $0.23(0.2-0.27)$ & $<0.001$ & $0.37(0.31-0.44)$ & $<0.001$ & 967 (79.7) & $246(20.3)$ & $0.52(0.42-0.64)$ & $<0.001$ & $0.49(0.38-0.65)$ & $<0.001$ \\
\hline \multicolumn{13}{|l|}{ Mandatory } \\
\hline No & $1359(49)$ & $1414(51)$ & Reference & & Reference & & $1016(74.8)$ & $343(25.2)$ & Reference & & Reference & \\
\hline Yes & $533(91.7)$ & $48(8.3)$ & $0.09(0.06-0.12)$ & $<0.001$ & $0.14(0.1-0.2)$ & $<0.001$ & $406(76.2)$ & $127(23.8)$ & $0.93(0.73-1.17)$ & 0.52 & $1.2(0.89-1.62)$ & 0.23 \\
\hline \multicolumn{13}{|l|}{ Time of day } \\
\hline Morning & $800(55)$ & $654(45)$ & Reference & & Reference & & $641(80.1)$ & $159(19.9)$ & Reference & & Reference & \\
\hline Afternoon & $1092(57.5)$ & $808(42.5)$ & $0.91(0.79-1.04)$ & 0.16 & $0.79(0.66-0.94)$ & 0.007 & 781 (71.5) & $311(28.5)$ & $1.61(1.29-2)$ & $<0.001$ & $1.18(0.92-1.52)$ & 0.20 \\
\hline \multicolumn{13}{|c|}{ Type of mask } \\
\hline Surgical & & & & & & & 770 (71.6) & $305(28.4)$ & Reference & & Reference & \\
\hline Cloth & & & & & & & $652(79.8)$ & $165(20.2)$ & $0.64(0.51-0.79)$ & $<0.001$ & $0.65(0.52-0.81)$ & $<0.001$ \\
\hline \multicolumn{13}{|l|}{ Gender } \\
\hline Female & $1190(61.2)$ & $753(38.8)$ & Reference & & Reference & & $896(75.3)$ & $294(24.7)$ & Reference & & Reference & \\
\hline Male & $702(49.8)$ & $709(50.2)$ & $1.6(1.39-1.83)$ & $<0.001$ & $1.75(1.51-2.04)$ & $<0.001$ & $526(74.9)$ & $176(25.1)$ & $0.98(0.79-1.22)$ & 0.86 & $1.03(0.82-1.29)$ & 0.79 \\
\hline \multicolumn{13}{|c|}{ Age category } \\
\hline$>65$ years & $451(66.8)$ & $224(33.2)$ & Reference & & Reference & & 357 (79.2) & $94(20.8)$ & Reference & & Reference & \\
\hline $41-65$ years & $724(61.1)$ & $460(38.9)$ & $1.28(1.05-1.56)$ & 0.015 & $1.34(1.08-1.68)$ & 0.008 & $578(79.8)$ & $146(20.2)$ & $0.96(0.72-1.29)$ & 0.78 & $0.85(0.63-1.15)$ & 0.28 \\
\hline $21-40$ years & $717(48)$ & $778(52)$ & $2.18(1.81-2.64)$ & $<0.001$ & $2.28(1.83-2.85)$ & $<0.001$ & 487 (67.9) & $230(32.1)$ & $1.79(1.36-2.37)$ & $<0.001$ & $1.47(1.1-1.98)$ & 0.01 \\
\hline
\end{tabular}

Outcome was assessed using multivariate logistic regression estimating odd ratios (ORs) and $95 \%$ confidence intervals (CIs). Crude and adjusted odds ratios determine the factors associated

with the use and the visual correct positioning of facemask fit. Values presented as number (\%). p < 0.05 was considered statistically significant. The multivariate model had no missing data. 